\title{
Mandative, Adverbial Subjunctive Complementizer Phrases and Argument Structure: A Contrastive Study Between Arabic and English
}

\author{
May Al-Shaikhli ${ }^{1 *} \quad$ Prof. Atef Jalabneh ${ }^{2}$ \\ 1.Department of English Language and Translation, Amman Arab University, Amman, Jordan \\ 2.Department of English Language, Al-Imam Mohammad Ibn Saud Islamic University, Riyadh, KSA
}

\begin{abstract}
The objective of this article is to differentiate between mandative complementizer phrases from adverbial subjunctive complementizer phrases whether they constitute argument structures to verbs or not in Arabic and English. As both phrases are initiated by complementizers, theoretically, the issue becomes a problem to decide whether every phrase initiated by a complementizer constitutes an argument structure or not though the complementizers might be deleted at LF in both languages. Thus, the researchers refer to Chomsky's (1981-1995) minimalist views to help us draw a clear distinction between them for better semantic interpretations at LF. The results illustrate that there are certain similarities and differences between the two languages; for instance, Arabic has mandative phrases that constitute argument structures but do not permit the complementizer ?an 'that' and the subjunctive marker [a] to be omitted at LF; likewise, English has mandative phrases that constitute arguments, but they permit the complementizer 'that' to be omitted at LF. Arabic has a unique independent adverbial subjunctive phrase initiated by ?anla 'not that', but it does not constitute an argument structure to any verb; however, English does not have this type of phrase. Arabic also has dependent adverbial subjunctive phrases initiated by the adjuncts (i) ?idh 'then', (ii) likai 'in order to', (iii) hatta 'until', li 'to' and li 'let'; they must be followed by the complementizer ?an 'that'; but, they do not form internal arguments to verbs. Arabic has a dependent complementizer phrase in the indicative initiated by ?ida 'if' which constitutes an argument and bears a theta role. Similarly, English has a dependent adverbial complementizer phrase initiated by the complementizer 'whether' / or 'if'; it constitutes an argument to a verb in the matrix clause, but it is always in the indicative form. Finally, though theoretically $\Theta$ - roles do not have [+ interpretable] power at LF, they must be assigned to arguments at spell-out to produce grammatical sentences at LF in both languages.
\end{abstract}

Keywords: $\Theta$ - roles, Argument structure, Spell-out, LF, Complementizers, Interpretable, Subjunctive

DOI: $10.7176 /$ JLLL/75-06

Publication date: January $31^{\text {st }} 2021$

\section{Introduction}

It is evident that English belongs to Proto - Germanic language family; it has the word order SVO whether the lexical verb is in the subjunctive or the indicative form (c.f. Lyons, 1981 p. 184-192). The language like any other languages in the world has both (i) the mandative subjunctive structures and (ii) adverbial clauses in its basic syntactic structures. The former type occurs, basically, in the embedded position of a particular base form of a finite verb; it is initiated by the unique particle (that); however, there is a lack of agreement in terms of third person singular between the subject of the embedded mandative clause and its lexical verb. Thus, the verb used in this kind of structure lacks the overt occurrence of the s- form marker at its end. In other words, there is no backshifting of tense to indicative form as the actual usual use of the English verbs in finite clauses. It is a productive type of structure due to the fact that the used verb provides the matrix clause with the required semantic stipulations of demand, recommendation, proposal, resolution ...etc. The mandative verbs that can project mandative subjunctive phrases in their embedded positions are many; therefore, the following list provides specimens of them: propose, decide, suggest, insist, order, prefer, request, recommend, demand, mandate ...etc. (c.f. Quirk et al 1985, p. 156-157). However, the latter type of structure, namely, adverbial phrases, is visible with the complementizer whether / or if; it occurs in the embedded position of certain verbs in the finite form such as ask, wonder, want, say, decide, sure... etc. It is evident that these verbs are in the indicative but not the subjunctive form and project different semantic components (c.f. Quirk et al, 1985, p. 155-157, 1182 and 1224).

However, Arabic; belongs to the Hamito - Semitic (Afro - Asiatic) language family; it is spoken in the northern area of the Sahara. It has, basically, the word order of VSO (c.f. Lyons, p. 191-192). Arabic has (i) mandative subjunctive structures as well as (ii) adverbial subjunctive clauses like other languages used in the world. Mandative structures are projected with certain verbs and occur in the embedded positions; they are initiated with the particle ?an 'that' and a finite verb to which the default accusative mood marker [a] is annexed. The language has a number of verbs that project these types of clauses; they include the specimens of yaqtarihu 'suggest', yamillu 'incline', yakrahu 'disincline', yakhāfu 'fear', yanwi 'intend', yafridu 'propose', yūşi 'recommend', yațlubu 'demand', $y \bar{u} s i_{i}$ 'mandate'... etc. (c.f. Wright (1984), Abdulhamid (1999) and Maghalsih (2007)). However, the adverbial 
clauses, in Arabic, are different in their structure components; they are (i) independent clauses and initiated with the particle la?an / or lan 'not that'; this conjoint has the polarity negative item la 'not' and the particle ?an 'that'. And, (ii) the dependent adverbial clauses which are initiated with the complementizers: (i) ?idh (?an) 'then that', (ii) kai (?an) 'in order to that', (iii) hatta (?an) 'until that' and (iv) li (?an) 'let that' and a finite verb in the subjunctive form. It also has a dependent adverbial clause initiated by the adjunct? ida 'if' in the indicative form. (c.f. Wright (1984), Abdulhamid (1999) and Maghalsih (2007)).

As this study focused on the semantic components of the projected clauses and other adverbial clauses that carry the same features in relation to argument structure, the researchers highlighted the problematic issues related to the objective of the study. It is clear that there are certain similarities and differences in the components of the mandative structures between the two languages to the extent it is difficult to decide the exact boundary of the projected clause that carries a semantic role; for instance, English permits the omission of the particle 'that' from the structure, but Arabic does not. In other words, the English sentence remains grammatical whether 'that' is overt or covert without affecting neither the structure nor the meaning of the sentence as in [John suggests he come in two-piece suit]. However, this syntactic issue is different in Arabic; mandative structures require the compulsory overt occurrence of the particle 'an 'that' at the initial position of the structure as well as the default subjunctive mood marker [a] at the end of the used verb. If any one of them is deleted, the resulting sentence is ungrammatical. For instance, we may have [ yussiru zaidun ?an ya?kul-a (subj.) 'Zaid insists that he eat'] but not [* yussiru zaidun ya?kul-a (subj.) 'Zaid insists he eat'. ] and [*yussiru zaidun ?an ya?kul (ø) 'Zaid insists that he eat' (c.f. Wright (1984), Abdulhamid (1999) and Maghalsih (2007)). Thus, whether the omission of the particles in the two languages affects the semantic component of the structures or not, it will be explicated with reference to different theoretical views in the subsequent sections

Another problematic syntactic issue is related to the nature of the verb that projects the mandative structure in the two languages. For instance, in Arabic, there are certain verbs that can project mandative structure in the subjunctive form but such verbs cannot project the same clause, in English. They include, (i) yamillu 'incline', (ii) yakrahu 'hate', (iii) yajibu 'must' and (iv) yuharramu 'prohibit', ... etc. For instance as a specimen [yajibu ?an $y a$ ? kul-a (subj.) zaidun 'Zaid that must eat']; such a structure cannot be used in English as in [* 'John must that eat']. These verbs, in Arabic, are different from the verbs of reporting as in [* qaala-?anna-hu yaquum-a (subj.) biwaajibi-hi 'he said that he perform his duty'] where the subjunctive mood marker [a] cannot occur. The sentence can be made grammatical if the indicative form of the verb is used, instead, as in [qaala-?anna-hu yaquum- $u$ (ind.) biwaajibi-hi 'he said that he performs his duty'] (c.f. Wright (1984), Abdulhamid (1999) and Maghalsih (2007)). As the projected clauses might carry different semantic components, they must be investigated in different perspectives.

\section{The Theoretical Literature Views}

As it is difficult to decide the argument structures and the semantic roles of the above structures in both languages, the researcher refers to Chomsky's theoretical views of (1981 and 1986b) to solve this syntactic as well as semantic issues. He argued that internal structures established at D- structure must be preserved at S-structure in a mechanism called structure preserving principle. Thus, a syntactic structure is required at D-structure will be present at S-structure as well. For instance, a position is required by the projection principle at D-structure will also be present at S-structure though certain components are deleted; for instance, a position projected a certain phrase at D-structure cannot change its category at S-structure or LF.

Chomsky (1986a, b and 1995) argued that the nature of tense [T] of the finite clause delimit the distinction between indicative and subjunctive phrases in a language. It has the value $[ \pm$ Tense], where [+Tense] stands for finite and [- Tense] for infinitival. Thus, the former consists of [C" and T"]; while, the latter has only [T"]. [C"], in X-bar syntax, is initiated with the complementizer [C], marked with a specifier and projects an inflectional phrase [T"] as a complement. A clause is typically having the structure [C" Spec [C' C [T" Spec [T' T V"]]]]. The [Spec, $\left.\mathrm{C}^{\prime \prime}\right]$ is optional and it occupies A' -position. The Extended Projection Principle (EPP) confirms that [Spec, $\left.\mathrm{T}^{\prime \prime}\right]$ is obligatory position for both matrix and embedded phrases occupied with the subject D"; thus, it is case position as well as A-position for theta- marking in the argument structure. Strong features are narrowly limited in distribution and represented by the functional category [T', T], the substantive category [D-] and the verb phrase [P-] that head the major projections within the clause and the complementizer phrases [Cs] that serve as moodforce indicators $(1995$, p. 379). Such features are drawn from the lexicon for numeration and needed to be checked in at all levels of syntax to guarantee the correct interpretation of the theta roles. Other [- interpretable] features, namely, the theta role manifestations in the argument structure are checked at spell-out but deleted at interface and LF because they are not part of numeration in the computational channel (1995, p. 377).

Chomsky $(1993,1995)$ argued that a lexical head projects the number of arguments it licenses and specifies what semantic role each argument receives. The association between $\theta$ - roles and argument positions is predictable; for instance, the agent $\Theta$ - role is assigned to the subject position rather that the complement position. The selectional restrictions play a central role in the interpretation of a sentence at LF. They specify intrinsic 
semantic features of the complements and subject. Thus, a verb with no $\Theta$ - role to assign to a complement will not be able to project a complement. However, a verb with obligatory theta roles to assign will have to occur in a configuration with enough arguments to receive $\Theta$ - roles. Hence, semantic selectional restrictions are determined by thematic properties. To get a $\Theta$ - role, the inherent semantic features of an argument must be compatible with that role. The complementizer phrase [C"], in X-bar syntax, is headed by a complementizer [C] and a specifier; but it must have tense clause [T"] of the matrix verb as a complement. As mentioned above, it has the structure of [C" Spec [C' C [T" Spec [T' T, V']]]]. A specifier of [Spec, C"] is optional; thus, it is a non - argument position in $\mathrm{X}$-bar syntax. $\Theta$ - theory is - a module of grammar that accounts for the assignment of $\Theta$ - roles to arguments determined with the lexical properties of the head verb. According to X-bar syntax, the lexical head of the maximal projection governs complements to which $\Theta$ - roles are assigned. [D"], [P"], [T"] and [C"] are $\Theta$ - role bearers; while, [A"], [Adv"], [Ps] and [Vs] are not. Arguments must occupy $\Theta-$ a positions in the argument structure to bear $\Theta$ - roles. They must be governed and assigned $\Theta$ - roles such as agent, patient, experiencer, location ...etc.

Radford $(1988,2002)$ argued that the verb in the mandative subjunctive is invariable; thus, it has neither overt tense nor [Agrs] though it is a pure finite clause. It is argued that in inflectional languages like Arabic, the subjunctive verb is inflected in both [T] and [Agrs] features simultaneously. As subjunctive clauses are clearly finite in nature in such languages, it is argued that on universal grounds it is possible to regard them finite in English also. English subjunctive clauses are treated finite as they share certain morpho-syntactic properties in common with indicative clauses which differentiate them from non-finite clauses. Theoretically, although a finite phrase is overtly or covertly inflected for tense and agreement features, subjunctive [I] lacks such features in English. Thus, subjunctive phrases require an overt complementizer at certain level whether tense is overt or covert in any clause to form [C"] in which [I"] node is visible. And, since [I"] constituent does not appear overtly in such structures, the obvious solution to be followed over here is that the subjunctive [C"s] have an empty [I]. This assumption leads to a final universal conclusion that says all clause that have [I'] can be filled by [I] if finite or left empty [e]. The empty [I] helps achieve the structural account of the nominative case checking to guarantee the grammaticality of the structure (Radford (1988, p. 307)

Jalabneh $(2007,2017)$ suggested that Arabic is dealt with in this work as SVO at spell-out but VSO at LF due to two primary syntactic as well as semantic reasons related to argument structure. Firstly, all conditions of government theory, namely, c- command and m-command relations are to be met for theta marking assignment. The imposition of the verb to the wright side of the verb is significant to meet c-selection and s-selection properties at all levels of syntax. Secondly, the thematic relations, namely, theta criterion and assignment of theta roles to arguments in [D", V"] are also to be met in this approach for correct semantic interpretation of the internal argument structures in Arabic. After theta roles are assigned, V-movement is essential to meet the word order of Arabic at the logical form [LF]. Thus, the above theoretical views will be our guide to explicate the mandative, adverbial subjunctive complementizer phrases in relation to argument structure in Arabic and English syntax.

\section{Problem of the Study}

Not all complementizer phrases mentioned above constitute argument structures and bear $\Theta$ - roles in both languages; thus, there is a difficulty to differentiate between them. Though mandative phrases and adverbial phrases are initiated by certain complementizers, theoretically, the issue becomes a problem to decide whether every phrase initiated by a complementizer constitutes an argument structure to a verb or not; thus, the complementizers might or might not be deleted at LF in both languages and the LF structure might look similar to each other in both languages.

\section{Objectives and Questions of the Study}

The objective of this article is to differentiate between complementizer phrases that form argument structures and check $\Theta$ - roles from those which do not in both types of phrases though both of them have the similar structures at LF in both languages insofar as the deletion of the complementizer is concerned; therefore, the following questions are proposed:

1. What type of complementizer phrases form arguments and what do not in both languages?

2. What are the $\Theta$ - roles assigned to them in both languages and how?

3. Why are $\Theta$ - roles important in syntax?

\section{Discussions and Results}

\section{a. Mandative Complementizer Phrases with $\theta$ - Roles in Arabic}

This type of phrase has the mandative subjunctive form; it occupies an argument position in the structure. In Arabic, it is initiated by a transitive verb and the complementizer ?an 'that'. Syntactically, it has the structure [V" Spec [V' V [C" Spec, [C' C [ T" Spec ]] in X-bar syntax. Though $\Theta$ - roles are informal features in syntax, they must be assigned to arguments at spell -out to produce grammatical sentences that have correct semantic interpretations at LF. As theoretically mentioned above, Arabic is dealt with in this work as SVO at spell -out but 
VSO at LF for the convenient of the theta - roles assignment. V-movement is applied to Arabic to get correct word order at LF (c.f. Jalabneh 2007 and 2017). We may look at the sentence (1) to show the process of $\Theta$ - role assignment in the argument structure.

Spell-out
1a. zaid -
un
yussir-
u ?an
ya -
$1^{\mathrm{c} a b}-$
a
$\varnothing$.
Zaid
nom
insist
pres. that agrs
play
'Zaid insists that he play.'

(1b) is the tree-diagram representation for (1a).

1.b

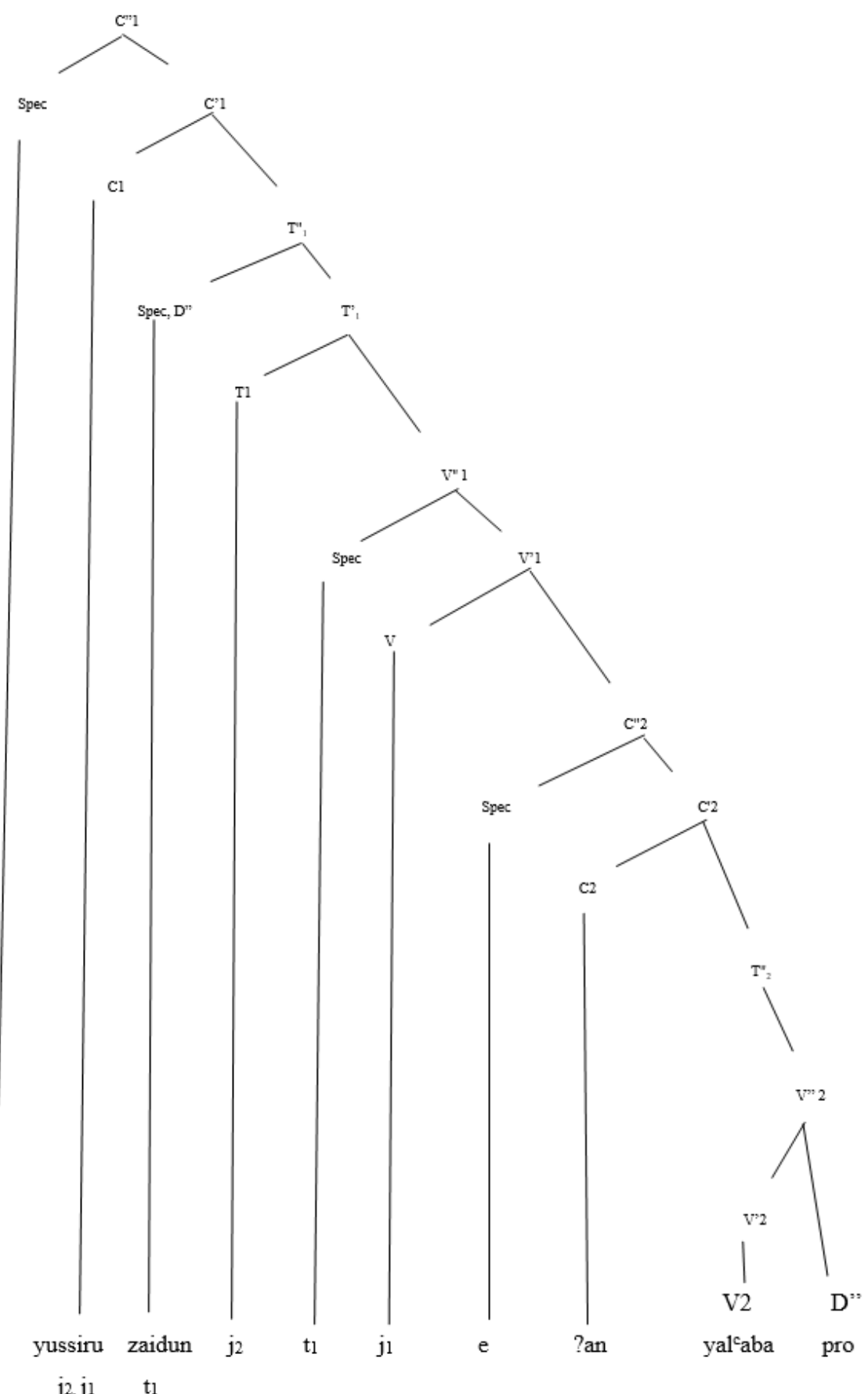

The sentence (1b) illustrates that the matrix transitive verb yussiru 'insists' projects the internal argument structure of [C" ?an yal'aba pro "that he play']; it is assigned the $\Theta$ - role of patient by the [ V" yussiru zaidun 'Zaid insists'] as it undergoes the action of insistence. As Arabic is a pro- drop - language, the argument pro 'he' is assigned the $\Theta$ - role of agent by the [V2] yalcaba 'play' as it wills the action of playing. To get correct word 
order at LF, the verb yussiru must move to the position of [T1, T'1] to check tense then in a cyclic movement to $[\mathrm{C} 1, \mathrm{C}$ '1] to meet the order of VSO in Arabic at LF. The argument pro in [C'2] is deleted but it is visible by the gender agreement marker [ya] pre-attached to the verb $l^{c} a b a$.

In case, the complementizer ?an 'that', in (1a), is deleted at spell out, the sentence will be interpreted ungrammatical in (1c) given below.

LF

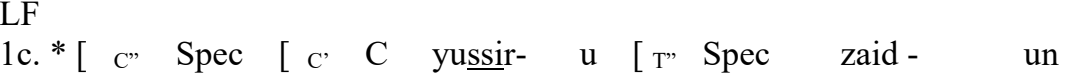

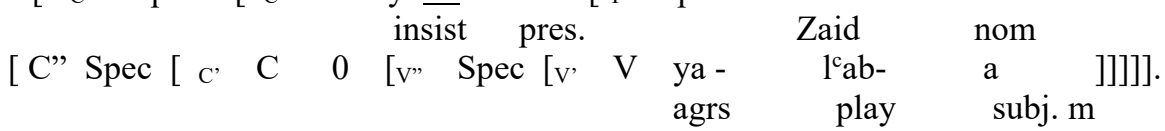

'* Zaid insists he play'

Likewise, if the complementizer ?an 'that' in the same sentence (1a) is retained and the subjunctive mood marker [a] is omitted, the resulting sentence is also ungrammatical as in (1d) given below.

LF

$$
\begin{aligned}
& \text { 1d. *[ C"Spec [ C C } \quad \text { C yussir- } \quad \text { u } \quad\left[\begin{array}{llll}
\text { T" } & \text { Spec } & \text { zaid - un }
\end{array}\right. \\
& \text { insist pres. Zaid nom } \\
& \text { [ C" Spec [ C C C ?an [v" Spec } \left.\left[\begin{array}{llllll}
\mathrm{V} & \mathrm{V} & \text { ya }- & \mathrm{l}^{\mathrm{c}} \mathrm{ab}- & \boldsymbol{0} & ]
\end{array}\right]\right] \text { ]. } \\
& \text { that agrs play subj. } \\
& \text { '* Zaid insists he play' }
\end{aligned}
$$

Obviously, in (1d), the overt occurrence of the complementizer ? an 'that' and the subjunctive mood marker [a] is obligatory; thus, they have one to one relation to guarantee the grammaticality of the sentence in Arabic syntax. In short, the overt occurrence of both the complementizer? an 'that' and the mood marker [a] is a must at all levels of syntax in Arabic syntax to form an argument structure of [C'2].

If the whole mandative complementizer phrase [C"2] ? an yalcaba pro 'that he play' that constitutes one argument structure is deleted, the result is the ungrammatical sentence (1e) as shown below.

LF

$$
\text { insist pres. }
$$

$$
\text { '* Zaid insists' }
$$

In short, the sentence (1e) confirms the obligatory application of the projection principle in which all phrases are projected at spell out; therefore, the verb yussiru 'insists' requires a complementizer phrase in its internal argument structure that has the theta grid of [agent (external), patient (internal)] as specified in (1a). The former is assigned to zaidun 'Zaid' and the latter to the whole complementizer phrase [C'2] [? an yal'aba pro 'that he play'].

In case, the verb yussiru in (1a) is used in other contexts other than the mandative subjunctive, its argument structure will be different as in (2) and (3) respectively.

Spell out

$2 \mathrm{a}$

[ T"Spec zaid - un [V"Spec [V, V yussir- u [P" cala al- tufaahat- i.

Zaid nom insist pres. on det apple loc

[ CoorP" wa- laysa [P" cala - al- tammrat - i ] ]]]]].

$$
\text { but not on det loc }
$$

LF

'Zaid insists on the apple but not on a piece of date'

2b. [C"Spec [C, C yussir- u [ T" Spec zaid - un [P" cala al- tufaahat- i insist pres. Zaid nom on det apple loc

[ coop" wa- laysa [P" cala - al- tammrat - i $]]]]]$ ].

but not on det date loc

'Zaid insists on the apple but not on a piece of date'

In (2a), the verb yussiru projects the $\Theta$ - grid of [agent, location]. The agent theta role is assigned to the external argument [ Spec, D"] zaidun 'Zaid'; while, the theta role of the location is assigned to the prepositional phrase [ ' ala al-tufaahati walaysa 'ala al-tamrati 'on the apple but not on a piece of date']. The sentence (2b) is the LF representation of (2a) after $\mathrm{V}$ - movement is performed in the course of derivation as mentioned above in (1b).

Spell out

3a. [ T" Spec zaid - un [v"', Spec [v, V yussir- u [P" cala [v"?akl- i

$\begin{array}{rrrr}\text { [D" al- } & \text { Zaid nom } \\ \text { det } & \text { tufahahat- } & \text { a }]]]]]] . \\ \text { acple } & \text { acc }\end{array}$

'Zaid insists on eating the apple' 


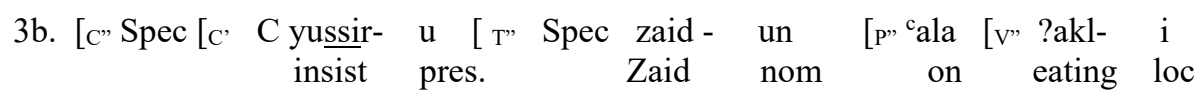
$\begin{array}{rll}\text { [D" al- } & \text { tufaahat- } & \text { a 1]]]]] } \\ \text { det } & \text { apple } & \text { acc }\end{array}$

'Zaid insists on eating the apple'

Likewise, in (3a), the verb yussiru 'insists' has the $\Theta$ - grid of [agent, location]; the former is assigned to the subject zaidun 'Zaid' in the position of [Spec, D'], but the latter to the prepositional complement cala ?akli al- tufaahata 'on eating the apple'. In this internal argument, the verb ?akla 'ate' assigns the $\Theta$ - role of patient to the internal argument al-tufaahata 'the apple' in the position of [V", D"].

In short, in (1-3), the type of $\Theta$ - role assigned to an argument in an argument position depends on the c-selection as well as s-selection properties of the verb used in the sentence. Therefore, the theta grid in (1) is different from (2) and (3) of the same verb yussiru 'insists'. Arabic has a number of verbs that c-select mandative subjunctive phrases as arguments that have the same theta role of patient in the internal position; they include: yaqtarihu 'suggest', yamiilu 'incline', yakrahu 'disincline', yakhaafu 'fear', yanwi 'intend', yafridu 'propose', yuuși 'recommend', yațlubu 'demand' and yantadibu 'mandate' and yufadilu 'prefer', yakrahu 'hate', yajibu 'must' and yuharrimu 'prohibit' ...etc. However, [V'] assign different theta roles to the external argument subject which are theoretically not a part of their argument structures. For instance, the verb phrases yakhaafu 'fear', yakrahu 'hate', yufadilu 'prefer' and yanwi 'intend' assign the theta role of experiencer to their external arguments because of psychological impact appears on the subjects. While, the rest of the italic verb phrases assign the theta role of agent to their subjects.

In case any other lexical verb of reporting nature is used, the mandative subjunctive form cannot occur as in (4) though [C"] is an internal argument to the verb.

4a. * [C" yaquulu- [C' zaid- un [C"? anna - [T" hu yaquum- a bi- waajibi- hi]]].

says Zaid nom that he perform- subj. with duty his

'Zaid said that he perform his duty.'

(4a) is ungrammatical not because [C"] ?anna - hu yaquuma biwaajibihi 'that he perform his duty' is the internal argument to the verb yaquulu 'says' and has the theta role of patient, but because the verb yaquuma 'perform' is marked with the default mood marker [a] of the subjunctive. It is evident that the verbs of reporting take the complementizer ? anna 'that', but not ?an 'that' in Arabic syntax as in (4b).

4b. * [C" yaquulu- [C, zaid- un [C"? an - [T" hu yaquum- a bi- waajibi- hi]]].

says Zaid nom that he perform- subj. with duty his

'Zaid said that he perform his duty.'

The sentence ( $4 \mathrm{~b})$ is wrong because the complementizer ?anna 'that' of reporting has been replaced by the complementizer? an 'that' of mandative adverbial and subjunctive argument structures.

The sentence (4a) can be made grammatical if the indicative form of the verb is used as in (4c).

4c. [C" yaquul- [C" zaid- un [C"?anna - [T" hu yaqaam- u bi- waajibi- hi]]]. said Zaid nom that he perform- past with duty his

'Zaid said that he performed his duty.'

If we made a contrast between the sentence (1) and (4) on syntactic basis, it is evident that the verb yussiru 'insists', in (1), requires the complementizer ?an 'that'; however, the verb qaala 'said', in (4), requires the complementizer? anna 'that'. The occurrence of the complementizers cannot be exchanged after the verbs since we get ungrammatical sentences in (5) and (6) in these specific structures respectively.

$$
\begin{aligned}
& \text { LF }
\end{aligned}
$$

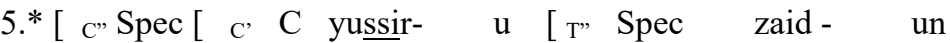

$$
\begin{aligned}
& \text { insist pres. Zaid nom } \\
& \text { [ C” Spec [ C' C ?anna [v" Spec [ } \left.\left.\left.\begin{array}{llllll}
\mathrm{V} & \mathrm{V} & \text { ya }- & \mathrm{l}^{\mathrm{c}} \mathrm{ab}- & \boldsymbol{\varnothing} & ]
\end{array}\right]\right]\right] \text {. } \\
& \text { that agrs play subj. } \\
& \text { 'Zaid insists he play' }
\end{aligned}
$$

\section{b. Mandative Complementizer Phrases with $\theta$ - Roles in English}

If we compare the mandative complementizer phrase discussed above in Arabic to English, we notice that the internal argument structure in the English sentence is initiated by the complementizer 'that' and projected by a transitive verb as in (7).

Spell-out

7a. [ T"Spec John [v" insists [ C"Spec [C, ${ }_{C}$ that [T" the council reconsider its decision ] ]]]. 
$7 b$.

Spell out

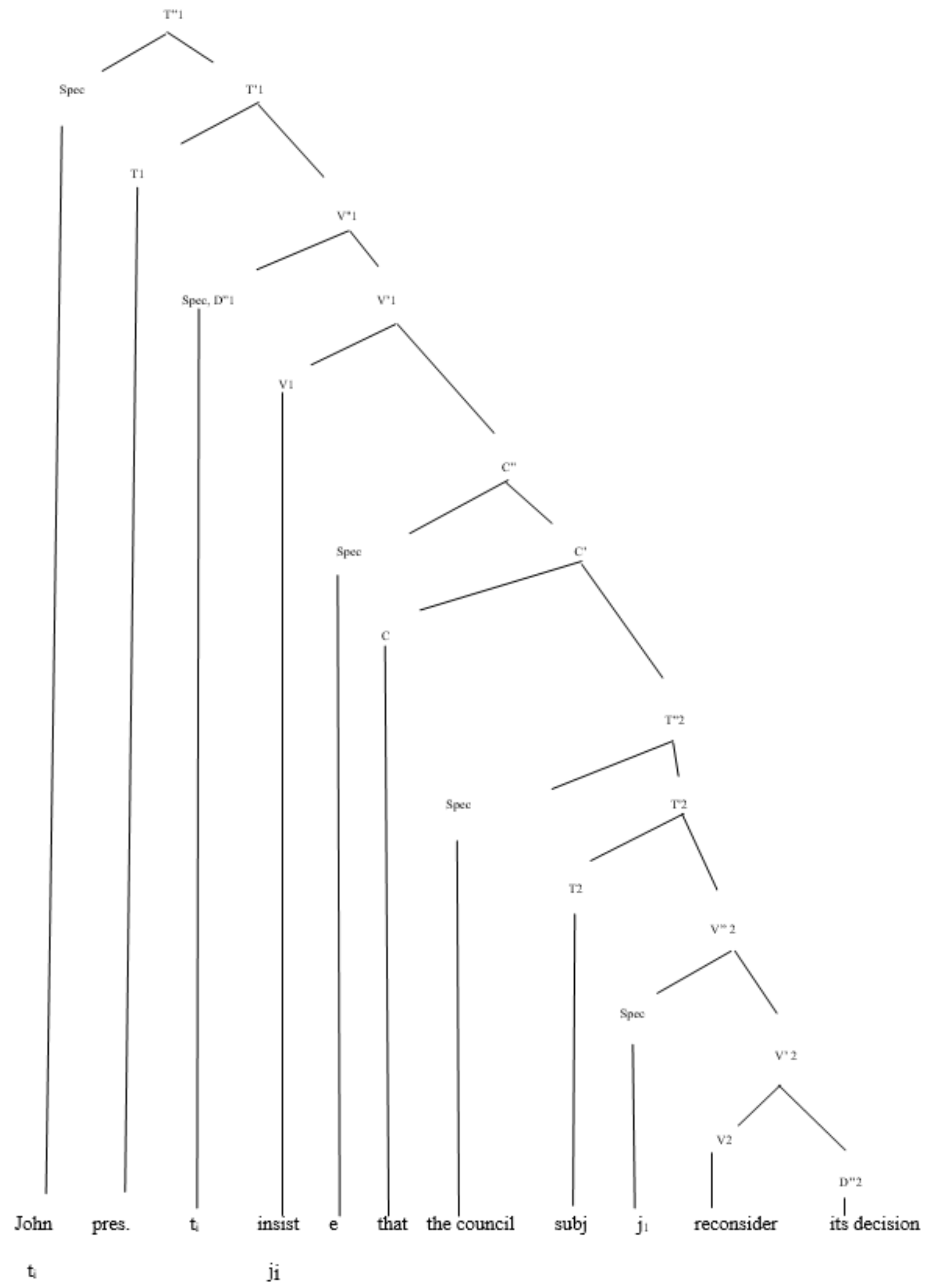


The sentence (7b) illustrates that the verb 'insists', in the position [V1, V'1], projects the subjunctive complementizer phrase 'that the council reconsider its decision' as its internal complement; it is assigned the $\Theta$ role of patient as it is the entity that undergoes the process of insistence. In this argument, the verb 'reconsider' in the of position [V2, V'2] assigns the $\Theta$ - role of patient to the [D'] 'its decision'. This complementizer 'that' might be deleted without affecting the grammaticality of the sentence as in $(7 \mathrm{c})$.

$\mathrm{LF}$

7c. [ T" Spec John [ V" insists [ C"Spec [ c' c Ø [T" the council reconsider its decision ]]]]. (Subjunctive, AmE) In short, the $\Theta$ - grid of the verb 'insists', in (7), is [agent (external) , patient (internal)] whether the complementizer is overt in (7b) or covert in $(7 \mathrm{c})$. Similar verbs that can project an internal argument whose theta role is the patient in English are: 'propose', 'decide', 'suggest', 'insist', 'order', 'prefer', 'request', 'recommend', 'demand', 'mandate', 'resolve', 'advise', 'desire', 'fit', 'move', 'require' ... etc. However, the external subject argument is assigned a different $\Theta$ - role based on the nature of the verb phrase used. For instance, the verbs 'prefer' and 'desire' assign the $\Theta$ - role of experiencer rather than agent as the subject experiences psychological impact. The rest of them assign the $\Theta$ - role of agent to the external subjects at spell -out.

However, the verb 'insist' may c-select other types of complementizer phrases as internal arguments whose verbs have the indicative form as in (8).

Spell-out

8a. [ T"Spec John [V" insists [ C" Spec [C, C that [T" the council reconsiders its decision ] ]]]. (Indicative, BrE).

$\mathrm{LF}$

8b. [ T"Spec John [ V" insists [ C"Spec [ C, C Ø [ T" the council reconsiders its decision ]]]].

The sentence (8a) shows the verb 'insist' has the internal argument 'that the council reconsiders its decision'; it is assigned the $\Theta$ - role of patient by the same verb. Similarly, the sentence (8b) is also grammatical even though the complementizer 'that' is deleted. This is because the overt tense phrase feature (i.e., s-form) is strong and guarantees the grammaticality of the sentence at LF.

The same verb projects also an internal argument whose verb is in the putative form as in (9). Spell-out

9a. [ T"Spec John [V" insists [ C"Spec [C, C that [T" the council should reconsider its decision ]]]]. (Putative, BrE) 9b. [ T" Spec John [ V" insists [ C"Spec [ C, C Ø [T" the council should reconsider its decision ]]]].

In (9a), the argument that has been selected by the same verb is 'that the council should reconsider its decision'; it is assigned the $\Theta$ - role of patient. Though 'that' is deleted, $(9 \mathrm{~b})$ remains grammatical. The difference between the two sentences is that in (7) the verb 'reconsider' has empty tense [e]; while, the verbs 'reconsiders' in (8) and 'should reconsider' in (9) have strong overt tense markers respectively [c.f. Radford, 1988]. The verb 'insist' may c-selects a prepositional phrase in (10).

10. [ T" Spec John [v" insists [p" on solving the problem]]].

In (10), the prepositional phrase 'on solving the problem' is assigned the $\Theta$ - role of location rather than the patient. Thus, (10) has the theta grid [agent, location] while the sentences (7-9) have [agent, patient].

In short, Arabic is like English in the sense that the mandative complementizer phrase constitutes an argument structure and is assigned the $\Theta$ - role of patient by all the verbs. $\Theta$ - roles are weak at LF even though they are essential for the grammaticality of the sentence in both languages. Thus, they are imposed at spell out as in (1) and (7) respectively. However, Arabic differs from English because the complementizer ?an and the accusative marker [a] cannot be deleted at all levels of syntax; whereas, in English, 'that' can be omitted at the logical form and the verb is unmarked for the subjunctive mood .

\section{Adverbial Subjunctive Complementizer Phrases in Arabic}

\section{i. Independent Phrases without $\boldsymbol{\theta}$ - Roles}

Arabic has an adverbial phrase whose adjunct is la? an / or lan 'not that'; this component has the component of the negative polarity item la 'not' and the complementizer ?an 'that'. The component lan heads an adverbial complementizer phrase whose occurrence is obligatory at spell out and other levels of syntax in as in (11).

LF

11a. [ Neg" Spec [ Neg' Neg la [C" Spec [C’ C ?an [T" ya- suuq- a

$$
\begin{array}{llll}
\multicolumn{2}{c}{\text { not }} & \text { that agr drive subj } \\
\text { zaid- un } & \text { al- } & \text { sayyarat- a ]]]]]. } \\
\text { Zaid nom } & \text { det } & \text { car acc } & \text { 'That Zaid does not drive the car.' }
\end{array}
$$

The sentence (11a) shows that the complementizer phrase lan yasuuqa zaidun al-sayyarata 'that Zaid does not drive the car' does not bear a theta role because there is no verb phrase to c-select it; thus, it does not constitute an argument to check a $\Theta$ - role. As a separate independent phrase that involves a verb and arguments in syntax, zaidun 'Zaid' is assigned the $\Theta$ - role of agent as it wells the action by [V'] yasuuqa al-sayyarata 'drive the car'], and the argument al-sayyarata 'the car' that occurs in the argument object position is assigned the theta role of patient as it undergoes the action of driving. It is similar to a mandative phrase in structure because neither the 
negative la nor the complementizer ?an can be deleted at any level of syntax.

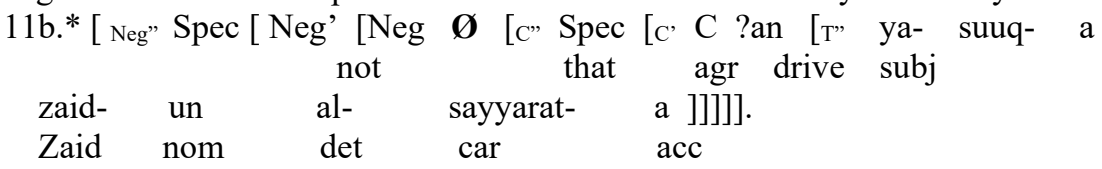

'That Zaid drive the car.'

Therefore, the sentence $(11 \mathrm{~b})$ is ungrammatical as the negative item la 'not' is deleted.

11c.* [ Neg" Spec [ Neg' Neg la [C"Spec [C, C Ø [T" ya- suuq- a

\begin{tabular}{lcccc} 
& & \multicolumn{2}{r}{ that } & agr drive subj \\
zaid- & un & al- & sayyarat- & a ]]]]]]. \\
Zaid nom & det & car & acc
\end{tabular}

Also, the sentence (11c) is ungrammatical because the complementizer ?an 'that' is omitted. However, if this Arabic phrase is compared to English, the latter does not have this type of complementizer phrase at all.

\section{ii. $\quad$ Dependent Phrases without $\theta$ - Roles}

Arabic has adverbial complementizer phrases initiated by certain adverbial adjuncts and followed by the complementizer? an 'that' other than the mandative and the independent phrases mentioned above. The adjuncts are listed as follows: (i) ? $\underline{i} \underline{d}$ 'then', (ii) likai / or kai 'in order to', (iii) hatta 'until', (iv) $l i$ 'to' and (v) li 'let'. The complementizer?an 'that' may / or may not appear after them at spell-out but not always at LF. For instance, (i) it is composed of the adverbial linker of time? idh 'then' and ?an 'that', (ii) the adverbial linker of purpose likai / or kai 'in order to' and (?an) 'that', (iii) the adverbial linker of time hatta and (?an) 'that' and (iv) the entity of suggestion $l i$ 'let' and (v) the preposition $l i$ 'to' and (?an) 'that'. We may explain the dependent adverbial subjunctive phrases in (12) and (13) as specimens from Arabic.

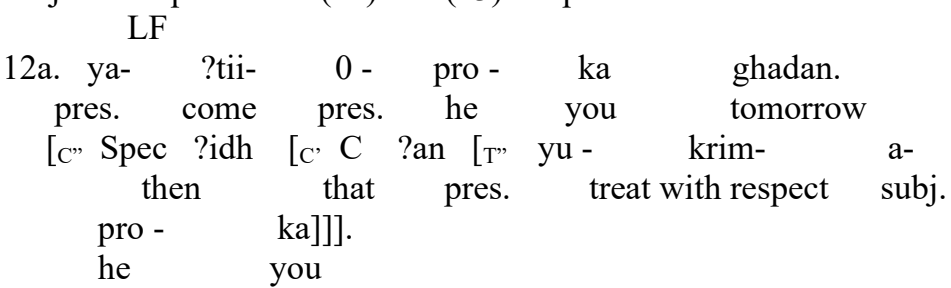

'He will come to you tomorrow then that he treat you with respect.'

(c.f. Wright, 10, Vol, ii, p. 33)

In (12a), the subjunctive phrase [?id? an yukrimaka 'then that the respect you'] is a dependent clause; although it is initiated by ?an 'that', it does not bear a $\Theta$ - role as it is not projected by any matrix verb in the sentence. As it has the verb yukrim 'respect' in syntax, $\Theta$ - roles are to be assigned to arguments. Thus, pro 'he' is assigned the $\Theta$ role of agent and the object $k a$ 'you' the goal. The clause is headed by the adverbial of time ?idh 'then' that occupies [C", Spec] position. As the two parts ?idh 'then' and ?an 'that' constitute one entity in X-bar syntax in Arabic i.e. [C"], none of them can be deleted at any level in Arabic syntax as in $(21 \mathrm{~b}, \mathrm{c})$.

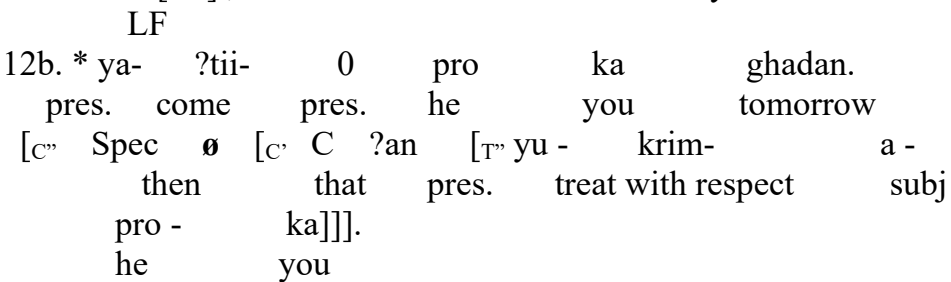

'He will come to you tomorrow that he treat you with respect.'

Thus, (12b) is ungrammatical since the adverbial adjunct ?idh 'then' that has been deleted.

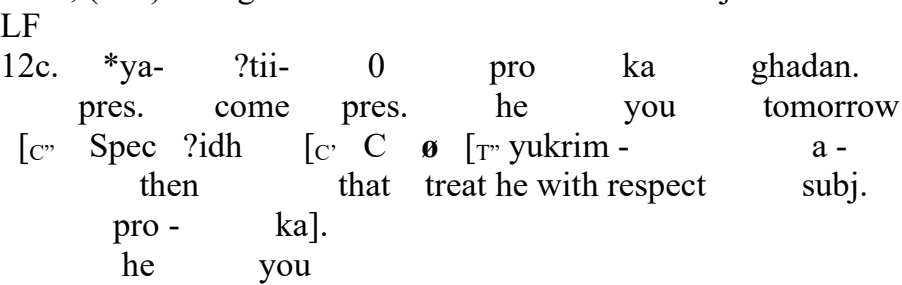

'he will come to you tomorrow then he treat you with respect.'

While, in (12c), it is ungrammatical since the complementizer ?an 'that' is deleted. In short, the adverbial ?idh and the complementizer? an have one to one relation in Arabic syntax. However, the situation is different in (13). LF

13a. yusjan- u al- lissu [C, Spec hatta [ $\begin{array}{lll}\mathrm{C} & \mathrm{C} & \text { ?an }\end{array}$ 


$$
\begin{aligned}
& \text { Jailed is pres. det thief until that }
\end{aligned}
$$

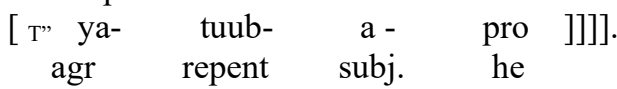

$$
\begin{aligned}
& \text { 'The thief is jailed until that he repent.' }
\end{aligned}
$$

In (13a), though the adverbial adjunct hatta 'until' followed by the complementizer ?an 'that' that initiates the subjunctive phrase hatta? an yutuuba 'until that he repent' occur, the phrase does not constitute an argument to bear a $\Theta$ - role; theoretically, it is not projected by any verb in the other clause. As a clause, it has its manner in terms of theta marking in syntax; therefore, the covert pronoun pro 'he' is assigned the $\Theta$ - role of experiencer by the verb yatuuba 'repent' as it exercises a psychological impact of repenting.

\section{LF}

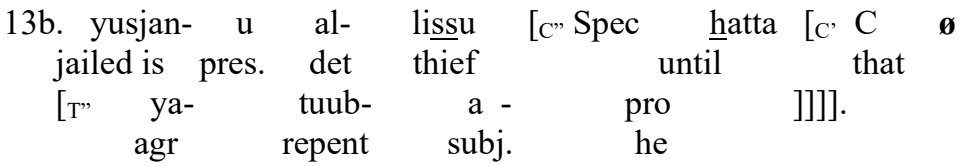

'The thief is jailed until he repent.'

The sentence (13b) is grammatical though the complementizer ?an 'that' is deleted; it is because the subjunctive marker [a] is retained. The adverbial of time hatta 'until' cannot impose the subjunctive mood marker [a] as contrasted to ?an 'that' which can at spell out level.

\section{LF}

13c. * yusjan- u al- lissu [C"Spec o $\left[\begin{array}{lll}\mathrm{C}^{\prime} & \mathrm{C} & \text { ?an }\end{array}\right.$ jailed is pres. det thief until that [ ya- tuub- a- pro ]]]]. agr repent subj. he

'The thief is jailed that he repent'

However, the sentence (13c) is incorrect because the adverbial adjunct hatta 'until' is omitted; thus, the complementizer? an and the subjunctive mood marker [a] cannot render a dependent grammatical sentence in Arabic syntax; also, the subjunctive phrase ?an yutuuba 'that he repent' must be subcategorized by a predicate to get a $\Theta$ - role in this sentence. In short, the sentences (12) and (13) prove that the adverbial complementizer phrases are both in the subjunctive and do not constitute arguments to verbs at the same time. The syntactic difference between the two sentences is the occurrence of the complementizer ?an 'that'. In (12a), it must not be deleted; while, it can be deleted, in (13b).

To avoid repetition, the adverbial adjuncts likai / kai + (?an) 'in order to that)', li (?an) 'to' and li (?an) 'let that)' are used as hatta 'until' in (13) but not as ? id ' 'then' in (12); the complementizer ?an 'that' may appear or not after them in the sentence as it is optional.

\section{iii. $\quad$ Dependent Phrases with $\theta$ - Roles}

Similar to English, Arabic comprises of a certain adverbial complementizer phrase initiated by the complementizer ? id a 'if' when, it occurs as a second internal argument in the embedded position of a transitive verb (Wright, 1984, p. 292-293 for usage of ?id). The phrase is in the indicative form but not the subjunctive. The sentence (14) below illustrates the issue.

\section{LF}

14a. yas?al - u zaidun [D", D' D camran [C", C, C ?ida yuriid - u al- ciba] ask pres. Zaid Amr if want pres. det play 'Zaid asks Amr if he wants to play'

The sentence (14a) illustrates that the verb sa? al 'ask' projects the theta grid of [ agent (external), goal, patient (internal)] arguments. The argument [D"] 'amran 'Amr' is assigned the theta role of goal; while, the argument [C"] ? $\underline{d} a$ ? araada al-laciba 'if he wanted to play' the theta role of patient.

$$
\text { LF }
$$

$$
\begin{aligned}
& \text { 14b.* yas?al - u zaidun [D", D, D 'amran [C", C' C } \\
& \text { ask past Zaid Amr if want pres. det play } \\
& \text { 'Zaid asks Amr if he wants to play' }
\end{aligned}
$$

The sentence (14b) is ungrammatical since the complementizer ?ida 'if' is omitted. LF

14c.* yas?al - u zaidun [D", D' D 'amran [C", C, C ?ida yuriid - a al- ciba]] ask past Zaid Amr if want subj. det play

'Zaid asks Amr if he want to play'

The sentence (14c) is ungrammatical since the complementizer ? $i \underline{d a}$ ' if' cannot propose the subjunctive mood at 
the end of the verb yuriid - $\boldsymbol{a}$ (subj) 'want'. In short, the dependent complementizer phrase initiated with ?ida 'if' constitutes an argument and gets a theta role by the used verb.

\section{Adverbial Complementizer Phrase in English}

\section{i. Dependent Phrases with $\Theta$ - Roles in English}

Though English does not have independent adverbial clauses as that of Arabic in (11), it has dependent adverbial complementizer phrases. If we compare the Arabic phrases in (12) and (13) to English, we find that English does not have such kind of phrases; however, if we compare the sentence (14) to (15) given below, we find similar structure insofar as the argument structure is concerned. English has the complementizer 'whether / or if' that initiates [C"] in the embedded position. It constitutes an argument and bears a theta role as in (15a).

15a. John asks Mary [C" [ C, C whether / if [T" T, T [Spec she [ V" V' V solves the problem or not]]]]].

The sentence (15a) indicates that the complementizer phrase 'whether/ if she solves the problem or not' is an argument to the verb 'asked'. It is assigned the $\Theta$ - role of patient. In this argument, the agent that role is assigned to the external subject 'she' with the verb phrase 'solves the problem or not'; while the theta role of patient is assigned to the argument 'the problem or not' with the verb 'solve'.

15b.* John asks Mary [C" [ C' C ø [T" T' T [Spec she [ V" V' V solves the problem or not]]]]].

If the complementizer 'whether/ or if' is deleted, the sentence becomes ungrammatical as in (14b).

15c.* John asks Mary [C" [ C, C whether / if [T" T, T [Spec she [ V" V, V solve- Ø the problem or not]]]]].

However, the sentence $(15 \mathrm{c})$ is also ungrammatical because the overt occurrence of the complementizer 'whether / if' cannot select the empty subjunctive mood marker [e] (c.f., Radford, 1988).

To sum up; Arabic has mandative phrases with argument structures but do not permit the complementizer ?an 'that' and the subjunctive mood marker [a] to be omitted; likewise, English has the same structures and properties but it permits the complementizer 'that' to be omitted in certain dialects. Arabic has independent adverbial phrase initiated with la? an / or lan 'not that' which does not constitute an argument to bear a theta role by a predicate; however, English does not have such a phrase. Arabic also, has dependent adverbial complementizer subjunctive phrases initiated by the adverbial adjuncts ?idhan, likai, hatta and li that do not form internal arguments to get theta role. It has a dependent phrase initiated by the complementizer ? ida 'if' that constitutes an internal argument and bears the theta role of patient in the structure. This kind of phrase is always in the indicative form but not the subjunctive mood. Similarly, English has a dependent adverbial complementizer phrase initiated by the complementizer 'whether' / or 'if'; it cannot be in the subjunctive mood, it is always in the indicative form. It constitutes an argument structure and bears the theta role of patient.

\section{Conclusion}

To achieve the objectives of the study, it was evident that the results showed that there are clear similarities and differences between mandative phrases and adverbial phrases in relation to argument structure formation in both languages. For instance, in Arabic, in (1), the mandative phrases constitute internal arguments to a predicate and bear theta roles. Neither the complementizer ?an 'that' nor the subjunctive mood marker [a] can be deleted. In case the same verb of mandative is used with different c-selection as well as s-selection, its theta grid will be different as it has been explained in (2) and (3). The results confirm that the verbs that project mandative argument structure take the complementizer [? an 'that' $+\mathrm{C}$ ']; while, the verbs of reporting though they project internal argument in the indicative form, they take the complementizer [? anna 'that' $+C$ "] as in (4). Any exchange of the complementizers after the verbs causes ungrammaticality to the sentences as in (5) and (6). Similarly, in English, the mandative argument structure is projected by a verb and the complementizer 'that' as in (7a,b). The difference between the two languages is that in English the complementizer 'that' can be deleted at LF without affecting the grammaticality of the sentence as per the American English as in $(7 \mathrm{c})$. Though the verb of mandative might project different theta grid other than the subjunctive [C"], still, [C"] remains the internal argument to the verb and bears a theta role whether the complementizer 'that' is overt as in ( $8 a)$ or covert as in $(8 b)$. This is because the indicative form [i.e., s- form] is overt at the end of the verb used. Similarly, the same verb of mandative subjunctive might project an internal argument of [C"] with putative illustrations as in (9a) in which this argument is the patient and the complementizer 'that' is overt. Likewise, in (9b), the same process of theta assignment is the same, but the complementizer 'that' is covert. The same verb might c-selects [P'] as its internal argument instead of [C']; thus, it is assigned the theta role of location as, in (10), but not the theme as that of [C"] elsewhere. Insofar as the adverbial subjunctive complementizer phrases are concerned, Arabic has a specific independent adverbial subjunctive complementizer phrase initiated by la?an / or lan 'not that' which does not constitute an internal argument to a verb in (11a); thus, it cannot bear a $\Theta$ role. It was significant to notice that neither the polarity negative article $l a$ 'not in (11b) nor the complementizer ? an 'that' in (11c) can be deleted. however, English does not have such kind of a phrase at all. Furthermore, Arabic has a dependent adverbial subjunctive complementizer phrase initiated with the adverbial adjunct ?idh 'then' and the complementizer ?an 'that' that does not constitute an argument; thus, it cannot bear a theta role as in (12a). In it, ?idh and ?an have one to one relation; therefore, 
they cannot be deleted as in (12b) and (12c) respectively. Arabic also has a dependent subjunctive phrase initiated by the adverbial adjunct hatta 'until' and the complementizer ?an 'that' that cannot bear a theta role since it is not subcategorized by a verb as in (13a). It is obvious that the complementizer ?an can be omitted at LF and the sentence remains grammatical as in (13b). However, if the adverbial hatta is deleted, the sentence renders ungrammatical as in (13c). To avoid repetition, the adverbial adjuncts likai / kai + (?an) 'in order to that)', li (?an) 'to' and $l i$ (?an) 'let that)' are used as hatta 'until' in (13) but not ? id 'then' in (12); the complementizer?an 'that' may appear or not after them in the sentence as it is optional. Arabic has a dependent complementizer phrase initiated by the complementizer ? $\underline{d} a$ 'if' in (14a) in which the verb yas?alu 'asks' projects the theta grid [Agent (external), goal, patient (internal)] arguments. The sentence becomes ungrammatical if the complementizer ? $i \underline{d}$ is deleted as in (14b). This complementizer cannot impose the subjunctive mood [a] at the end of the embedded verb yuriid - a (subj.) 'want'; therefore the sentence (14c) is ungrammatical. Likewise, in English, it has the adverbial complementizer phrase that is initiated with 'whether / or if'; it initiates [C"] as internal argument in the embedded position of the verb 'ask' and bears a theta role as in (15a). If the complementizer 'whether'/ or 'if' is deleted, the sentence becomes ungrammatical as in (15b). However, the sentence (15c) is also ungrammatical because the overt occurrence of the complementizer 'whether' / 'if' cannot allow it to select the empty subjunctive mood marker [e]. Thus, it is always in the indicative form. To sum up, though $\Theta$ - roles do not have [+ interpretable] power at LF, they are intrinsic in syntax and must be checked at spell-out to produce grammatical sentences at

\section{Appendix. 1}

Table 1. Transliteration Symbols of Arabic Consonants Phonemes

\begin{tabular}{|c|c|c|c|}
\hline Arabic & Transliteration & Arabic & Transliteration \\
\hline أ & $?$ & ض & $\mathrm{d}$ \\
\hline ب ب & $\mathrm{b}$ & b & $\mathrm{t}$ \\
\hline 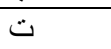 & $\mathrm{t}$ & ظ & $\mathrm{Z}$ \\
\hline$\dot{H}$ & th & $\varepsilon$ & $\mathrm{c}$ \\
\hline ج & $\mathrm{j}$ & $\dot{\varepsilon}$ & gh \\
\hline$\tau$ & $\underline{\mathrm{h}}$ & ف & $\mathrm{F}$ \\
\hline$\dot{\tau}$ & $\overline{\mathrm{kh}}$ & ق & $\mathrm{q}$ \\
\hline د & $\mathrm{d}$ & ك & $\mathrm{k}$ \\
\hline$\dot{j}$ & $\underline{\mathrm{d}}$ & $J$ & 1 \\
\hline$\jmath$ & $\mathrm{r}$ & 5 & $\mathrm{~m}$ \\
\hline$j$ & $\mathrm{Z}$ & ن & $\mathrm{n}$ \\
\hline س & $\mathrm{sh}$ & 9 & $\mathrm{~W}$ \\
\hline ص & S & ي & $\mathrm{y}$ \\
\hline
\end{tabular}

Notice : the researchers have a reference to the transliteration symbols while writing the Arabic phonemic segments in the text. (c.f. Oxford Journal for Islamic Studies) 


\section{Appendix. 2}

Table 2. Transliteration Symbols of Arabic Vowels Phonemes

High Central

back

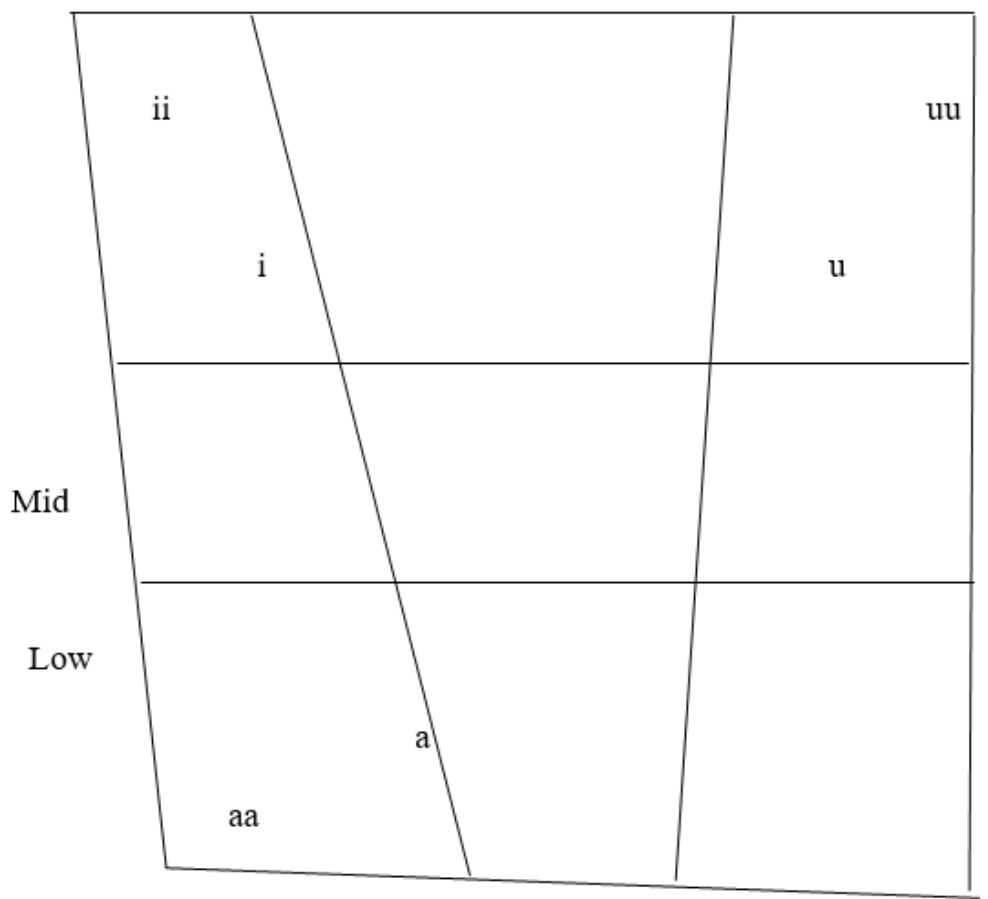

(c.f. Oxford Journal for Islamic Studies)

\section{Appendix 3}

\section{Abbreviations}

Acc: Accusative

A" : Adjectival Phrase

A' : Adjectival Phrase Bar

A : Adjectival

Adv": Adverbial Phrase

Adv' : Adverbial Phrase Bar

Adv : Adverb

Agr: Agreement

Agrs: Agreement Subject

c-Selection: Constituent Selection

C": Complementizer Phrase

$\mathrm{C}^{\prime}$ : complementizer Bar Phrase

$C^{\prime}$ : complementizer Phrase

D": Determiner Phrase

D' : Determiner Phrase Bar

Det : Determiner

LF : Logical Form

Loc : Locative

Nom : Nominative

P ": Prepositional Phrase

P' : Prepositional Phrase Bar

$\mathrm{P}$ : Preposition

Pres. : Present

S-selection : Semantic Selection

SVO : Subject, Verb, Object,

Sg. : Singular

Spec : Specifier

Subj.m : Subjunctive Masculine 
$T^{\prime \prime}$ : Tense Phrase

$T^{\prime}$ : Tense Bar

$\mathrm{T}:$ Ttense

V" : Verb Phrase

$V^{\prime}$ : Verb Bar

Vs: Verbs

VSO: Verb- Subject- Object

\section{References}

Abdulhamid, M. (1999), Shrah Ibn ${ }^{c}$ aqil ${ }^{c}$ ala Alfiyat Ibn Malik. Cairo. Maktabat Dar Al-Turath.

Chomsky, N. (1981). Lectures on government and binding. Dordrecht: Foris

Chomsky, N. (1986a), Knowledge of language: Its nature, origin, and use. New York: CBS Educational and Professional Publishing.

Chomsky, N. (1986b), Barriers. Cambridge: MIT press.

Chomsky, N and Lasnik, H. (1993), The theory of principles and parameters. In Syntax: An international handbook of contemporary research, ed. by Joachim Jacobs, Arnim von Stechow, Wolfgang Sternefeld, and Theo Vennemann, 506-569. Berlin: de Gruyter. Reprinted in Noam Chomsky, The Minimalist Program, Cambridge, Mass.: MIT Press, 1995.

Chomsky, N (1995), The minimalist program. Cambridge, Mass: MIT press.

Jalabneh, A. (2007), The thematic relations in Arabic and English syntax. Jordan: Dar Al- Hadatheh for publication. Jalabneh, A. (2017), Case theory and Arabic prepositions. Germany: Noor publication.

Lyons, J. (1981), Language and linguistics: An introduction. USA: Cambridge University Press.

Maghalsih, M. (2007), Al-Nahu Al-Shafi Al-Shamil. Amman-Jordan: Dar Al-Masirah:

Quirk, R. et al. (1985), Comprehensive grammar of the English Language. New York: Longman.

Radford, A (1988), Transformational grammar. New York: Cambridge University

Radford, A. (2002), Syntax: a minimalist introduction. New York: Cambridge University Press.

Wright, W. (1984), Grammar of the Arabic language. New Delhi: S. Chand and Company. 